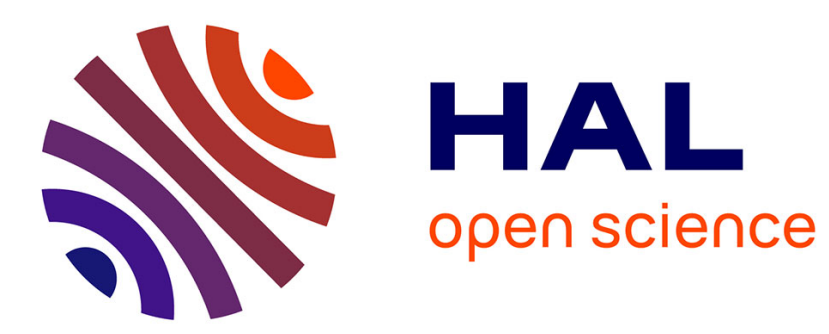

\title{
Revisiting the cost escalation curse of nuclear power: New lessons from the French experience
}

\author{
Lina Escobar Rangel, François Lévêque
}

\section{To cite this version:}

Lina Escobar Rangel, François Lévêque. Revisiting the cost escalation curse of nuclear power: New lessons from the French experience. 2012. hal-00780566

\section{HAL Id: hal-00780566 \\ https://hal-mines-paristech.archives-ouvertes.fr/hal-00780566}

Preprint submitted on 24 Jan 2013

HAL is a multi-disciplinary open access archive for the deposit and dissemination of scientific research documents, whether they are published or not. The documents may come from teaching and research institutions in France or abroad, or from public or private research centers.
L'archive ouverte pluridisciplinaire HAL, est destinée au dépôt et à la diffusion de documents scientifiques de niveau recherche, publiés ou non, émanant des établissements d'enseignement et de recherche français ou étrangers, des laboratoires publics ou privés. 
Interdisciplinary Institute for Innovation

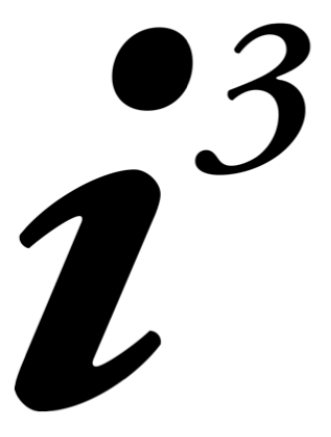

\section{Revisiting the cost escalation curse of nuclear power New lessons from the French experience}

Lina Escobar Rangel

François Lévêque

\section{Working Paper 12-ME-08}

December 3, 2012

CERNA, MINES ParisTech 60 boulevard Saint Michel

75006 Paris, France 


\title{
REVISITING THE COST ESCALATION CURSE OF NUCLEAR POWER. NEW LESSONS FROM THE FRENCH EXPERIENCE
}

\author{
Lina Escobar Rangel, François Lévêque ${ }^{\dagger}$
}

December 3, 2012

\begin{abstract}
Since the first wave of nuclear reactors in 1970 to the construction of Generation III+ reactors in Finland and France in 2005 and 2007 respectively, nuclear power seems to be doomed to a cost escalation curse. In this paper we reexamine this issue for the French nuclear power fleet. Using the construction costs from the Cour des Comptes report, that was publicly available in 2012, we found that previous studies overestimated the cost escalation. Although, it is undeniable that the scale-up ended up in more costly reactors, we found evidence of a learning curve within the same size and type of reactors. This result confirms that standardization is a good direction to look, in order to overcome the cost escalation curse.

Keywords: French nuclear power, construction cost, learning effects
\end{abstract}

${ }^{*}$ Centre d'Economie Industrielle. École des Mines de Paris. 75006, Paris, France. E-mail: lina.escobar_rangel@mines-paristech.fr

${ }^{\dagger}$ Centre d'Economie Industrielle. École des Mines de Paris. 75006, Paris, France. E-mail: francois.leveque@mines-paristech.fr 


\section{Introduction}

The cost escalation that has characterized the construction of new nuclear power plants seems to put into question the economic viability of this technology as part of the energy mix in different countries.

In the case of the U.S, where 104 nuclear reactors have been installed, the overnight cost in $\mathrm{USD}_{2010} / \mathrm{MW}$ for the first unit was 7 times less than the one for the last reactor. This phenomenon has been widely studied in economic literature ${ }^{1}$, and the general understanding is that the decentralized and heterogeneous way in which the nuclear fleet grew and the stricter safety rules that the Nuclear Regulatory Commission set after Three Mile Island accident ${ }^{2}$ are the main drivers of the U.S cost escalation.

In turn, France has the second largest nuclear fleet worldwide (58 reactors) and its nuclear program has been catalogued as a success. According to David and Rothwell (1996), the centralized and monolithic industrial structure has been the key element in avoiding the U.S cost escalation path. Likewise, Grubler (2010) argued that due to this centralized institutional setting, the nuclear fleet in France grew rapidly, substantially and systemically.

However, when the French construction cost were analyzed by Grubler (2010), he found an important cost escalation. The comparison between the construction costs in $\mathrm{FF}_{98} / \mathrm{kW}$ for the units installed in 1974 and the post 1990 constructed reactors, yielded in an increase by a factor of about 3.5. This finding suggested that even under the best conditions as prevailing in France (i.e. centralized decision making, high degree of standardization and regulatory stability), cost escalation is inherent to nuclear power.

Nowadays, history is repeating itself. The cost escalation is confirmed with the construction of the first Generation III+ reactors. In Finland, the original fixed-price contract for the Olkiluto $\mathrm{EPR}^{3}$ was for $€ 3$ billion in 2003 , which meant a cost prevision of $€_{2010} 2.100 / \mathrm{kW}$. In 2010 , the costs were revised and it was acknowledged that they had reached $€_{2010}$ 5.7 billion (i.e. $€_{2010} 3.500 / \mathrm{kW}^{4}$ ).

${ }^{1}$ See Komanoff (1981), Zimmerman (1982), Cantor and Hewlett (1988), McCabe (1996) and Cooper (2012),

2 See Cantor and Hewlett (1988) and Cooper (2012)

${ }^{3}$ European Pressurized Reactor

4 http://www.nirs.org/reactorwatch/newreactors/eprcrisis31110.pdf 
Similarly, the initial cost of the Flamanville EPR reactor in France increased from to $€_{2010} 3.3$ billions to $€_{2011} 6$ billions, with an expected delay of 9 years $^{5}$. These construction costs represent $€_{2010} 3.650 / \mathrm{kW}$, that is to say, almost three times the $€_{2010} 1.250 / \mathrm{kW}$ of the last N4 nuclear reactor built in France (Civaux).

For the Westinghouse AP1000 the story is the same. According to Parsons and Du (2009), the overnight costs registered in the applications submitted to the Nuclear Regulatory Commission lie between USD 2010 $3.650 / \mathrm{kW}$ and $\mathrm{USD}_{2010} 5.100 / \mathrm{kW}$. This represent at least a $75 \%$ increase with respect to the $\mathrm{USD}_{2010} 2.400 / \mathrm{kW}$ estimated in 2003. More recently, Rosner and Goldberg (2011a) from the University of Chicago also updated their previous study and estimated an average cost for the AP1000 equal to $\mathrm{USD}_{2010} 4.210 / \mathrm{kW}$.

In addition, we have seen an important decrease in the costs of competing energy technologies, which undermines even more nuclear power competitiveness. On the one hand, the prices of natural gas have decreased significantly due to the use of shale gas in the U.S; and on the other, renewables have registered important learning effects. For instance, Lindman and Söderholm (2012) found that the $\mathrm{kW}$ coming from wind farms decreases more than $10 \%$ every time that the installed capacity doubles.

On top of that, we may expect that Fukushima-Daiichi accident to have consequences in terms of cost. Safety authorities might impose stricter licensing rules and/or greater public opposition to installing new nuclear power plants could induce delays and therefore cost overruns.

So far, it seems that there is no escape from this curse. But before giving up, it is worth reviewing the French experience using the new data that is available. It is important to mention that Grubler made his cost assessment using estimations based on an annual investment report of Électricité De France (EDF) from 1972 to 1998. At the time of this publication, reliable data on the cost of the French nuclear program were not available.

Only until the beginning of 2012, the past construction and R\&D expenses related to French nuclear power were publicly available, due to a request from the Prime Minister to the national audit agency Cour des Comptes. This report brought together all the data concerning the

\footnotetext{
5 http://www.lemonde.fr/planete/article/2011/11/10/ sur-le-chantier-de-l-epr-a-flamanville-edf-est-a-la-moitie-du-chemir 1602181_3244.html
} 
actual construction costs for the 58 reactors installed in France. Using this data, the cost escalation is less severe that what was argued.

In the light of this result, in this paper we reexamine the cost drivers for the French nuclear power program using the data of Cour de Comptes report. We investigate the existence of scale and learning effects, as well as the relation between safety performance and costs. We propose to use a principal component regression approach to deal with the multicollinearity among the main explanatory variables.

Our results suggest that neither the scale-up nor cumulative experience induced cost reductions, but we have found a positive learning effect within similar types of reactors. This finding supports the idea of standardization as a strategy to reduce the cost overruns linked with uncertainty in the construction of complex technologies. Additionally, we found that those reactors with better performance, in terms of safety, are related with higher costs; thus improvements in safety unsurprisingly, can also be considered as a driver of the cost escalation.

The rest of the paper is organized as follows. Section 2 describes the data and its sources, then sets out the model and estimation procedure. The results are presented in Section 4. Finally, Section 5 concludes.

\section{Construction cost escalation: Data and Model}

After the publication of the Cour de Comptes report, we studied the EDF investments for the second generation of reactors, that accounts the actual construction costs of the 58 commercial units currently operating ${ }^{6}$, to compare them with previous studies, estimate a cost function and investigate its main drivers.

Figure 1 compares the official data with the estimated costs computed by Grubler (2010). We can conclude that the figures for the first reactors are quite accurate but those for the latest ones were overestimated. This discrepancy means a difference of 5.21 between the annual average rate of growth using Grubler s costs estimations expressed in $€_{2010} / \mathrm{kW}$, and the one using the Cour de Comptes construction costs. For the former, we found an average annual increase equal to $8.97 \%$ and for the latter, we got an increase of $3.76 \%$ on average per year.

${ }^{6}$ See Appendix A 


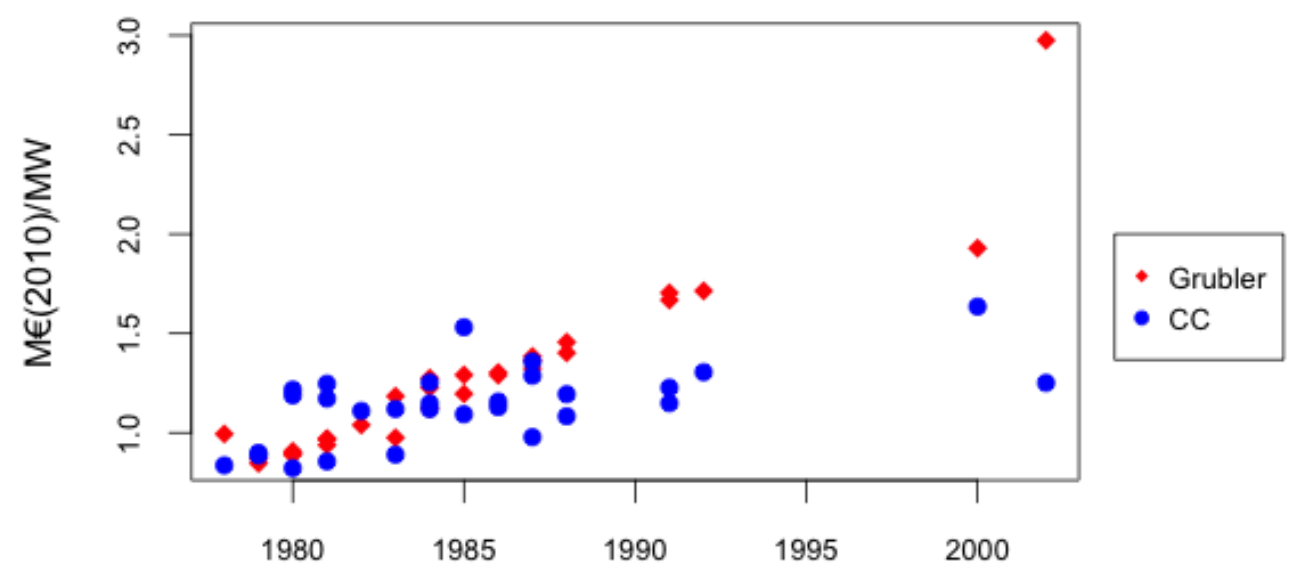

Figure 1: Grubler vs Cour de Comptes construction costs

As mentioned before, technological heterogeneity is viewed as one of the main explanations for the cost escalation in the U.S Two types of technologies (Pressurized Water Reactor and Boiling water reactor) have been installed and practically all of the units have customized sizes and designs. In contrast, the French nuclear fleet is considered to have a high degree of standardization, characterized by three different paliers. This categorization collects reactors by size. The first one comprises 34 installed reactors, all of them have 900MW nameplate capacity. The second palier includes 20 reactors with $1300 \mathrm{MW}$ and the last one contains 4 reactors with 1450 MW of installed capacity.

On top of that, within each palier it is possible to find different types of reactors. The first palier has 3 types of reactors CP0, CP1 and CP2. Although all of them have the same capacity, they differ in the conception of their intermediary cooling systems. In the second palier, there are two types of reactors $\mathrm{P} 4$ and $\mathrm{P}^{\prime} 4$ which differ in the layout of the structure that contains the fuel rods and the circuitry. Finally, in the last palier there is only one type of reactor, called N4. This design not only differs in capacity with the rest of reactors, but also in the conception of the steam generators, primary pumps and command room $^{7}$.

Figure 2 shows the construction cost in $€_{2010} / \mathrm{MW}$ for the French nuclear plants per type of reactor. It is clear that the cost escalation in France is also related to changes in the installed technologies. The

7 For a detailed description of the differences between the paliers and types, see http://rapport-annuel2010.asn.fr/fichiers/Chap_12_2010.pdf 

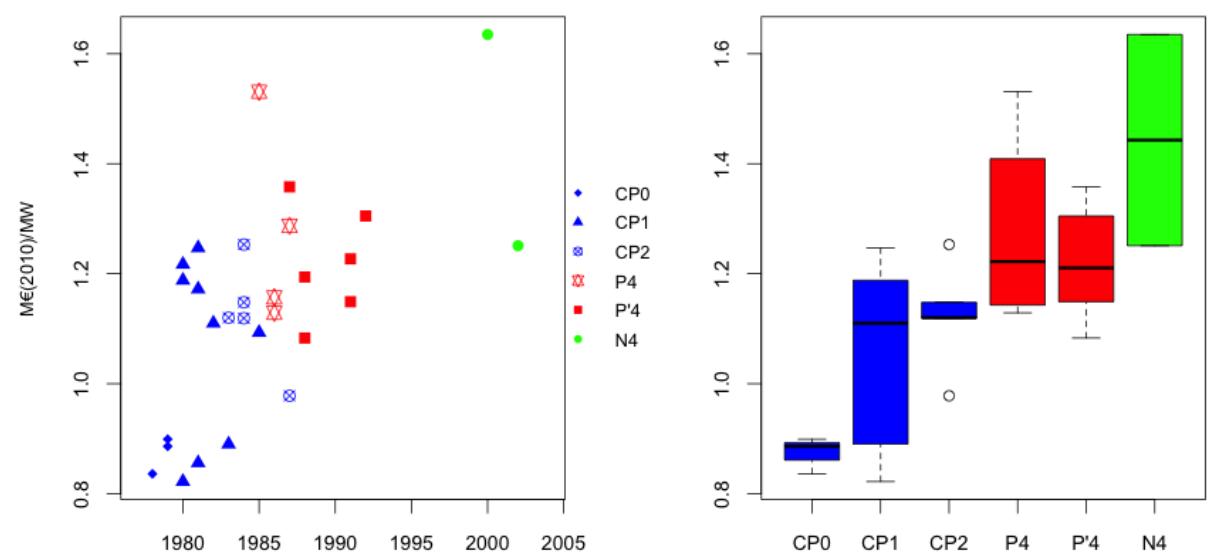

Figure 2: Cour de Comptes construction cost by Palier and Type

average cost for the first series of reactors (CP0) was the smallest, and it continuously increased as other types were installed. In this sense, Grubler (2010) stated that the high cost escalation towards the end of the program is precisely the result of the "gradual erosion of EDF determination to standardize".

By using a linear regression model, we seek to determine the construction cost main drivers. We assume a Cobb-Douglas cost function in which the explanatory variables are: capacity, experience, safety performance indicators and finally a random error.

$$
\begin{aligned}
\ln \left(C_{i}\right)= & \beta_{0}+\beta_{1} \ln \left(\text { Cap }_{i}\right)+\beta_{2} E X P I_{i}+\beta_{3} E X P P_{i}+\beta_{4} E X P T_{i} \\
& +\beta_{5} U C L_{i}+\beta_{6} U S 7_{i}+\beta_{7} \ln \left(\text { LTime }_{i}\right)+u_{i}
\end{aligned}
$$

Where:

- $C_{i}$ : Construction cost for the pair of units $i$ in $€_{2010}$ per MW

- $\operatorname{Cap}_{i}$ : Installed capacity in MW

- LTime $_{i}$ : Construction leadtime in months

- $E X P I_{i}$ : Number of completed reactors at the time of the construction of plant $i$ 
- $E X P P_{i}$ : Number of completed reactors within the same palier at the time of the construction of plant $i$

- EXPT : Number of completed reactors within the same type at the time of the construction of plant $i$

- $U C L_{i}$ : Lifetime average Unplanned Capability Loss Factor for unit $i$

- $U S 7_{i}$ : Lifetime average Unplanned Automatic Scram for unit $i$

Regarding capacity, in the U.S case the evidence against scale effects is conclusive. Zimmerman (1982), Krautmann and Solow (1988), Cantor and Hewlett (1988) and McCabe (1996) found that the construction of larger reactors ${ }^{8}$ increased the cost per MW installed. According to Cantor and Hewlett (1988), bigger units increase project complexity, subjecting them to managerial problems and stricter regulatory scrutiny. The positive correlation of lead time and size thus result in higher costs per MW.

On the contrary, the effect of the overall experience variable in construction costs is diverse. Komanoff (1981) and Zimmerman (1982) found positive evidence of a learning curve. They however recognized that the multicollinearity between the time trend and industry-cumulated experience, might bias their estimates.

This issue was solved by introducing the experience at firm level (constructor) and dummy variables to differentiate the management regime (utility or outsider). The learning effects were significant only when utilities constructed the plant ${ }^{9}$.

Given that EDF has been the only builder and utility, it is not possible to distinguish between industry and firm experience or to include dummies for management regimes. Nevertheless, we can distinguish experience within paliers and types of reactors. Therefore, to test the presence of learning effects, we considered three variables. The first took into account the overall experience $(E X P I)$, the second variable only

8 Except by Komanoff (1981) pioneering study that suggested a cost decline by $13 \%$ when doubling reactor's size; nevertheless subsequent papers rejected this result.

${ }^{9}$ This striking result was addressed later by Cantor and Hewlett (1988) and McCabe (1996). The former suggested that the market power of experienced firms allow them to charge higher prices, so the learning effects are kept as savings, whereas the latter found that what explains this difference are the poor incentives of the costplus contracts under which nuclear plants were procured to external constructors. 
added the previous reactors made within the same palier $(E X P P)$ and the last one accounted the reactors of the same type $(E X P T)$.

Besides of scale and learning effects, one could also be interested in identifying whether the cost escalation is linked with safety improvements. According to Cooper (2012), safety variables (fines and the number of safety standards and rules adopted by the NRC) are the most consistent predictors to explain the cost escalation in the U.S. In previous studies (Komanoff (1981), Zimmerman (1982), Cantor and Hewlett (1988), McCabe (1996)), safety improvements were related with the stringency of the regulatory agency which was represented with a time trend always found to be significant and positive.

For the French case it is hard to measure regulatory activity. The Autorité de Sûreté Nucléaire (independent regulatory agency) was created in 2006, 4 years after the last reactor was built in 2002. Additionally, Grubler (2010) found that there was no regulatory documented incidence from 1970 to 1999. However, Finon (2012) recognized that despite the stability in the French safety rules, EDF integrated safety reinforcements gradually into new reactors.

To test if safety improvements are related to construction costs, we included in the model two safety performance indicators defined by The World Association of Nuclear Operators (WANO) and adopted by the International Atomic Energy Agency (IAEA).

The first one is Unplanned Capability Loss Factor $\left(U C L_{i}\right)$, which reflects a reactor's ability to maintain the reliability of systems and components. This indicator belongs to the first category of the safety performance indicators used by the IAEA, that seeks to quantify how smoothly the plant operates. The $U C L$ indicator shows the percentage of energy that the plant was not capable of supplying due to deviations form normal operations.

The second indicator is Unplanned Automatic Scram $\left(U S 7_{i}\right)$, which belongs to the second category defined by the IAEA. Within this group, all the indicators quantify if the plant operates at low risk. The US7 tracks number of automatic shutdowns during one year (7.000 hours) of operation. We have chosen this measure because it gives a direct indication of the frequency of actual challenges to the systems, that submit plant equipment to extreme thermal loads and increase the risk of serious accidents.

In addition to the Cour de Comptes data, we have also gathered data 
from the Power Reactor Information System (PRIS) database published by the IAEA. We have taken the installed capacity in MW, the year in which the reactor was constructed, the construction period length (in months), the number of reactors that were built by EDF previously to account the experience, and the average lifetime UCL and US7 for each pair of units. Descriptive statistics of the data are presented in Table 1.

Table 1: Descriptive statistics

\begin{tabular}{llrrrrr}
\hline Variable & Unit & Mean & Median & Minimum & Maximum & Std \\
\hline Ln Cost & $\operatorname{Ln}\left(€_{2010} / \mathrm{MW}\right)$ & 0.119 & 0.138 & -0.196 & 0.491 & 0.170 \\
Ln Cap & Ln $(\mathrm{MW})$ & 7.656 & 7.517 & 7.461 & 7.987 & 0.196 \\
EXPI & \# reactors & 27.413 & 26 & 1 & 56 & 17.307 \\
EXPP & \# reactors & 12.034 & 12 & 1 & 30 & 8.974 \\
EXPT & \# reactors & 5.103 & 4 & 1 & 16 & 4.169 \\
UCL & \% & 7.127 & 7.075 & 3.075 & 11.959 & 2.083 \\
US7 & events/7000 hours critical & 0.773 & 0.690 & 0.180 & 1.40 & 0.3169 \\
LTime & Ln(months $)$ & 151.931 & 143 & 115 & 288 & 37.183 \\
\hline
\end{tabular}

\subsection{Multicollinearity and Principal Component ap- proach}

One of the main problems identified in the literature of nuclear construction cost escalation is the multicollinearity between explanatory variables included in the cost function, in particular the high correlation between installed capacity, industry experience and leadtimes.

To deal with this problem, Zimmerman (1982) suggested to use a monotonic transformation of overall experience instead of the original variable. In subsequent studies, such as those of Cantor and Hewlett (1988) and McCabe (1996), the issue was solved by taking the builder's experience into account instead of the overall industry experience, which eased the high correlation among these variables.

For the French case the multicollinearity problem is severe. There is a single builder (EDF), the scale-up was progressive and bigger reactors experienced greater leadtimes. As we can observe in Table 2, these three variables (Capacity, Overall experience and leadtime) are highly correlated, which warns the difficulty of obtaining significant results in a linear regression framework. 
Table 2: Correlation Matrix

\begin{tabular}{lrrrrrr}
\hline & Ln Cap & EXPI & EXPP & EXPT & Ln Ltime & US7 \\
\hline Ln Cap & 1 & 0.87 & -0.45 & -0.24 & 0.82 & -0.08 \\
EXPI & 0.87 & 1 & 0.03 & -0.02 & 0.77 & -0.23 \\
EXPP & -0.45 & 0.03 & 1 & 0.55 & -0.32 & -0.29 \\
EXPT & -0.24 & -0.02 & 0.55 & 1 & -0.23 & -0.22 \\
Ln LTime & 0.82 & 0.77 & -0.32 & -0.23 & 1 & -0.23 \\
US7 & -0.08 & -0.23 & -0.29 & -0.22 & -0.23 & 1 \\
\hline
\end{tabular}

Indeed, when we include all of them in a linear regression, the coefficients are imprecisely estimated (See Table 3). On top of that, we find high estimates for the Variance Inflation Factor (VIF), which confirms that the multicolinearity problem is severe.

Table 3: Linear regression estimates

\begin{tabular}{ccccc}
\hline Coefficients & Estimate & Std. Error & $\mathrm{t}$ value & $\operatorname{Pr}(>|t|)$ \\
\hline (Intercept) & 7.700 & 10.034 & 0.767 & 0.451 \\
Ln Cap & -0.252 & 1.216 & -0.208 & 0.838 \\
EXPI & 0.017 & 0.014 & 1.206 & 0.241 \\
EXPP & -0.002 & 0.015 & -0.186 & 0.854 \\
EXPT & -0.006 & 0.008 & -0.743 & 0.465 \\
Ln LTime & 0.261 & 0.344 & 0.761 & 0.455 \\
UCL & -1.410 & 0.882 & -1.598 & 0.125 \\
US7 & -0.009 & 0.018 & -0.487 & 0.632 \\
\hline
\end{tabular}

Table 4: VIF for explanatory variables

\begin{tabular}{ccccccc}
\hline Ln Cap & EXPI & EXPP & EXPT & Ln LTime & UCL & US7 \\
\hline 87.808 & 93.856 & 29.501 & 2.143 & 8.257 & 24.520 & 2.328 \\
\hline
\end{tabular}

The traditional way of solving multicollinearity problems is to eliminate one or more explanatory variables. We have tried different specifications. Nevertheless they did not result in significant estimates and the VIF remained high. The results of these models are shown in Appendix B.

Unfortunately, within this framework it is not possible to figure out the main drivers, because our data set appears redundant. By using a 
principal component regression, we overcame this limitation. With this method we can obtain relevant information from our data set, reducing it to a lower dimension and making it possible to reveal simplified underlying correlations between the costs and the explanatory variables.

Principal component analysis is an ancient multivariate technique developed by Pearson (1901) and Hotelling (1933). In economics this method has been applied in a wide range of subjects ${ }^{10}$, for instance, in macroeconomics and finance (Fifield and Sinclair, 2002), development (Zanella and Mixon, 2000) and socio-economic indexes (Filmer and Pritchett, 2001).

The main idea of this procedure is to take the correlation matrix, that we are going to denote by $\mathbf{C}=\mathbf{X}^{\prime} \mathbf{X}$ (where $\mathbf{X}$ is the $n \times k$ matrix of centered and scaled explanatory variables) and compute the $k \times k$ eigenvector matrix ${ }^{11} \mathbf{V}$.

Given that $\mathbf{V} \mathbf{V}^{\prime}=\mathbf{I}$, we can rewrite a lineal model $Y=X^{\prime} \beta^{*}$ as follows.

$$
\begin{gathered}
Y=\beta_{0}^{*} \mathbf{1}+\mathbf{X V V}^{\prime} \beta^{*} \\
Y=\beta_{0}^{*} \mathbf{1}+\mathbf{Z} \alpha
\end{gathered}
$$

Where $\mathbf{Z}$ is the $n \times k$ matrix of principal components. This matrix contains the same information that $\mathbf{X}$ but the columns are arranged according their share in the variance. Each principal component is a linear combination of the explanatory variables. The weights are defined by the characteristic vectors or loadings (matrix $\mathbf{V}$ ) and the roots (eigenvalues), denoted by $\lambda$, identify the most important components (the higher the eigenvalue, the higher the share in the variance).

Once this decomposition is done, the next step in this framework is to eliminate the principal components (columns of $Z$ ) associated with the smallest eigenvalues $(\lambda)$ in order to reduce the variance that is causing the multicollinearity and be able to estimate significant coefficients.

\footnotetext{
${ }^{10}$ We do not pretend to give a comprehensive list of principal component analysis in economics, rather to mention some examples.

${ }^{11}$ Recall that the eigenvectors of a square matrix $\mathbf{A}$ are defined as the vectors that solve $\mathbf{A W}=\lambda \mathbf{W}$, where $\lambda$ is a real or complex number called eigenvalue. They can equivalently be defined as the vectors that solve $(\mathbf{A}-\lambda \mathbf{I}) \mathbf{W}=\mathbf{0}$
} 


\section{Results}

The characteristic vectors and roots for the correlation matrix of the model $^{12}$ are presented in Table 5 .

Table 5: Eigenvectors and eigenvalues of Model 1

\begin{tabular}{cccccccc}
\hline & Comp 1 & Comp 2 & Comp 3 & Comp 4 & Comp 5 & Comp 6 & Comp 7 \\
\hline Ln Cap & 0.563 & & 0.180 & & -0.211 & -0.410 & 0.651 \\
EXPI & 0.522 & 0.172 & 0.299 & 0.338 & -0.144 & -0.220 & -0.652 \\
EXPP & -0.219 & 0.493 & 0.228 & 0.702 & & 0.157 & 0.374 \\
EXPT & -0.162 & 0.473 & 0.482 & -0.564 & -0.409 & 0.174 & \\
Ln LTime & 0.556 & & & & 0.211 & 0.794 & \\
UCL & & -0.558 & & 0.249 & -0.716 & 0.312 & \\
US7 & -0.134 & -0.430 & 0.765 & & 0.459 & & \\
\hline$\lambda$ & 81.309 & 66.434 & 20.658 & 13.796 & 10.206 & 3.464 & 0.131 \\
\hline
\end{tabular}

This decomposition can be interpreted as follows. The first component is the most important because it explains the highest share of variance and, the variables with the highest loadings are those that explain the major trend in the data. The subsequent components show the correlations within variables, independent of previous components.

In our case, the first component explains $41 \%$ of the total variance and has high loadings from: capacity, cumulative experience and leadtime. This component represents what Cooper (2010) denominated as the Bupp-Derian-Komanoff-Taylor hypothesis. This hypothesis states that as nuclear power industry (vendors and utilities) gained experience, bigger reactors were made and this technological scaling-up induced greater complexity which resulted in longer leadtimes.

The second component accounts for $33 \%$ of the variance. The variables with high loadings are experience within palier and type and the two safety performance indicators. Given that in this component the loadings have opposite signs, constructing similar reactors (either in size or type), made improvements possible in terms of safety indicators in the latest units.

If we check the scores ${ }^{13}$ we can compare the reactors within each

\footnotetext{
${ }^{12}$ We have also consider a model without the variable of experience at the palier level $\left(E X P P_{i}\right)$. The results are shown in Appendix $\mathrm{C}$

${ }^{13}$ The scores represent the linear combination of the explanatory variables in each principal component for each observation
} 


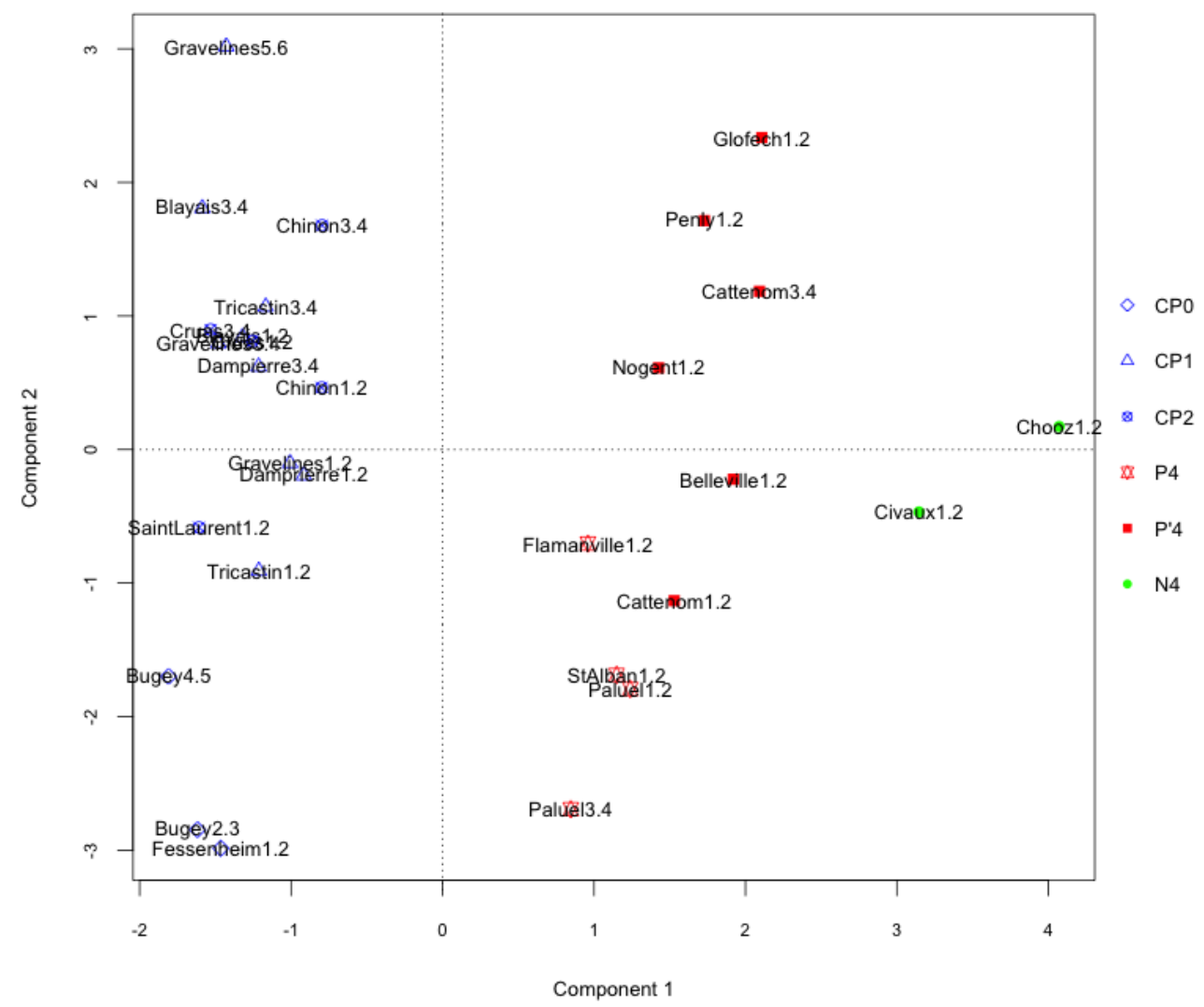

Figure 3: Scores of the first two components

component. In Figure 3 the scores for the first component are plotted on the horizontal axis. We can clearly see that they are clustered at the palier level, this result simply confirms the fact that bigger reactors were built as the industry gained experience but it took more time to construct them.

The second component is plotted on the vertical axis of the same Figure. Remember that this component represent the negative correlation between experience (in similar reactors) and safety performance. We can see that within each type, the units with higher scores are the latest in their series (more experience and better performance). For instance, Gravelines 5.6 and Blayais 3.4, correspond to the latest CP1 reactors. It is also the case for the $\mathrm{P} 4$ and $\mathrm{P}$ '4 series, where the reactors at Flamanville, Golfech and Penly were built after those installed at the Saint Alban, Cattenom and Belleville sites, respectively. For the same reason, 
it is no surprise that reactors such as Fesshenheim, Dampierre and Cattenom have small scores in this component, given that they can be seen as prototypes in their respective series.

To select the number of components to be included in the estimation, we chose the root mean squared error of prediction (RMSEP) criterion. Using the leave-one-out cross-validation method, we found that the RMSEP is minimized with the first two components.

Once the number of principal components had been selected, we computed the coefficients for the original linear regression. In Table 6 we present the estimates for our explanatory variables ${ }^{14}$.

Table 6: Principal Component Regression Results

\begin{tabular}{lrrrrrc}
\hline Coefficients & $\hat{\beta}^{*}$ & $\hat{\beta}$ & s.e $(\hat{\beta})$ & t-value & p-value & \\
\hline Ln Cap & 0.206 & 1.050 & $(0.280)$ & 3.747 & $1.11 \mathrm{e}-03$ & $* * *$ \\
EXPI & 0.209 & 0.012 & $(0.002)$ & 4.084 & $4.90 \mathrm{e}-04$ & $* * *$ \\
EXPP & -0.046 & -0.005 & $(0.002)$ & -2.177 & $4.04 \mathrm{e}-02$ & $*$ \\
EXPT & -0.026 & -0.006 & $(0.002)$ & -2.706 & $1.28 \mathrm{e}-02$ & $*$ \\
Ln LTime & 0.212 & 0.995 & $(0.255)$ & 3.898 & $7.72 \mathrm{e}-04$ & $* * *$ \\
UCL & -0.075 & -0.036 & $(0.004)$ & -8.199 & $3.91 \mathrm{e}-08$ & $* * *$ \\
US7 & -0.081 & -0.257 & $(0.041)$ & -6.215 & $2.95 \mathrm{e}-06$ & $* * *$ \\
\hline
\end{tabular}

In the light of these results, we confirm that as in the U.S case, the scaling-up of the French nuclear program did not translate in cost reduction. This is a well known phenomenon in nuclear power, since the construction of larger reactors is more complex, hence such a project implies greater risk of cost overruns (Cooper (2010)). The principal component approach shows that the strong correlation among capacity, overall experience and leadtime represents the main driver to explain the cost escalation. Table 6 shows that an increase in the installed capacity will induce higher construction cost per MW.

Regarding overall learning effects, we also found that cumulated experience had not induced a reduction in costs. This result is often seen as a consequence of the intrinsic characteristics of nuclear power, i.e. lumpy investments and site-specific design (Cooper (2010), Grubler (2010)).

\footnotetext{
${ }^{14}$ Given that we have had to standardized our explanatory variables, we differentiate the coefficients for the centered and scaled matrix with $\hat{\beta}^{*}$ and we use $\hat{\beta}$ for the original data.
} 
As mentioned before, Cooper (2010) suggests that with the construction of a new reactor, the experience gained by vendors and operators translates in adjustments and improvements, that complexify the reactors and make the new designs more expensive than their predecessors. In the French case, Grubler (2010) and Finon (2012) argue that the potential learning effects from the overall industry experience were not fully exploited, precisely because as they gained experience, it was decided to construct an entirely new French nuclear reactor.

Nevertheless, when we take into account the experience within the same palier and type, we find a positive learning effect. In Table 6, we can see that the estimates for these variables are negative, however their effect was less significant than the other variables.

The intuition behind learning effects within type of reactor is straightforward, but is less clear at the palier level, precisely because the reactors within them are not the same. A possible justification is that, each palier represents also a phase of the French nuclear program. Hence, the reactors within them were conceived and built during the same time window, which suggests that suppliers, workers and engineers did not change substantially during the construction of one palier, but they might have changed between them.

The negative sign in the experience variables means that some cost reductions were achieved due to standardization. Building similar reactors reduced the technological uncertainty linked with the adoption of a new design. This result can thus been seen as one of the potential sources of savings for future nuclear reactors, as well as one of the key differences between the U.S and France cost escalation drivers.

An other important result shown in Table 6, is that reactors with better safety indicators (UCL and US7) are related with higher costs. Therefore, we have some evidence that the latest reactors, although more expensive, have also embodied safety improvements.

\section{Conclusion}

In this paper, we sought to use the Cour de Comptes report to identify the main drivers of the construction cost escalation in France.

It was originally believed that the cost escalation was about a factor of 3.5, when comparing the unit costs from the units built in 1974 and those 
finished after $1990($ Grubler $(2010))$. Using the new data, we found that the escalation was about a factor of 1.5 between the first and the last unit, thus the escalation was less severe and by no means comparable with the U.S case. Therefore, important lessons can be drawn from this program in order to identify the elements that should be taken into account to overcome or at least mitigate the cost escalation phenomenon.

On the basis of the analysis using the Cour des Comptes data, there is every reason to believe that the construction cost escalation is mainly due to the scaling-up strategy. It induced greater complexity and leadtimes which in turn meant an increase in costs per MW. As mentioned before, the absence of scale economies in nuclear power is not a new result, and with the construction of new Generation III and III + reactors it is confirmed that larger reactors are more expensive. Hence, capacity could be one of the starting points in rethinking nuclear power strategy.

In this sense, several authors as Kessides (2012) and Rosner and Goldberg (2011b) have outlined the advantages of installing small modular reactors. They argued that these reactors have shorter construction schedules and lower market risk which reduces the cost of capital. Additionally, they considered that other cost savings can be achieved through off-site modules fabrication, as well as the learning by doing after the production of multiple modules.

This is in line with our results about learning effects. We found that overall experience did not traduce in lower costs but some gains were achieved due to the construction of same types of reactors. Given the nature of this result, it would appear likely that standardization is a strategy to overcome delays and uncertainties during the construction process and thus reduce the cost of the following reactors of the same series.

In view of the results regarding the safety indicators, it appears likely that reducing the risk of a serious accident has also played its part in the French cost escalation, as it was found by Cooper (2010) for the U.S case. Our model shows that in the conception of new nuclear reactors, safety improvements are undertaken (reflected in better safety indicators). In consequence when safety concerns are partly internalized in the construction costs, safer reactors are inherently more expensive.

For this reason, the economics of safety is perhaps the most challenging issue for the future of nuclear power. On the one hand, the terrible consequences of a nuclear disaster, such as the ones seen after Fukushima-Daiichi accident, leave no room for laxity. On the other 
hand, the particular nature of serious nuclear accidents, huge damages but very low and uncertain probability of occurrence, makes it difficult to determine if the safety investments are cost-effective.

Once again, the French case teaches us an important lesson. Principal component analysis showed that the latest units of the same series have better performance in terms of the safety indicators used in the model. In this sense, standardization besides generating learning effects in the construction process, can also play a role in terms of achieving better safety levels.

Small reactors also seem to have some advantages in safety terms, given that as Kessides (2012) pointed out, a simpler design leads to a lower frequency of accident initiators and a lower core power density induce a more effective use of passive safety features, that are those system components that do not require operator control or electronic feedback in order to shut down safely in case of an emergency.

In summary, the cost escalation curse in nuclear power may have a solution. Taking into account the lessons from French nuclear program, a good strategy would be to limit the number of technologies to be installed in order to obtain learning effects not only in construction costs but also in operations, in particular in safety performance. It should also be considered that new technologies, as the small modular reactors, bring the possibility of reducing the scale of the units as well as off-site module fabrication, thereby reducing the complexity and leadtimes that have been consistently found to be the main drivers of the cost escalation phenomenon.

\section{References}

Cantor, R. and Hewlett, J. (1988), 'The economics of nuclear power: Further evidence on learning, economics of scale and regulatory effects', The Bell Journal of Economics 13, 297-310.

Cooper, M. (2010), Policy challenges of nuclear reactor construction, cost escalation and crowding out alternatives. Unpublished manuscript.

Cooper, M. (2012), Nuclear safety and nuclear economics. Unpublished manuscript.

David, P. and Rothwell, G. (1996), 'Standardization, diversity and learning: Strategies for the coevolution if technology and industrial 
capacity', International Journal of Industrial Organization 14, 181201.

Fifield, P. and Sinclair (2002), 'Macroeconomic factors and share returns: an analysis using emerging market data', International Journal of Finance 86 Economics 7, 51-62.

Filmer, D. and Pritchett, L. (2001), 'Estimating wealth effects without expenditure data or tears: An application to educational enrollments in states of india', Demography 38, 115-132.

Finon, D. (2012), L'économie du nucléeaire revisitée. Unpublished manuscript.

Grubler, A. (2010), 'The cost of the french nuclear scale-up: A case of negative learning by doing', Energy Policy 38, 5174-5188.

Hotelling, H. (1933), 'Analysis of a complex of statistical variables into principal components', Journal of Educational Psychology 24, 417-441.

Kessides, I. (2012), 'The future of the nuclear industry reconsidered: Risk, uncertainties and continued promise', Energy Policy 48, 185208.

Komanoff, C. (1981), Power Plant Cost Escalation Nuclear and Coal Cost, Regulation and Economics, Van Nostrand Reinhold Publishing.

Krautmann, A. and Solow, J. (1988), 'Economies of scale in nuclear power generation', Southern Economic Journal 55, 70-85.

Lindman, A. and Söderholm, P. (2012), 'Wind power learning rates: a conceptual review and meta-analysis', Energy Economics pp. 754-761.

McCabe, M. (1996), 'Principals, agents and the learning curve: The case of steam-electric power plant design and construction', The Journal of Industrial Economics XLIV, 357-375.

Parsons, J. and Du, Y. (2009), Update on the cost of nuclear power, Technical report, MIT.

Pearson, K. (1901), 'On lines and planes of closest fit to systems of points in space', Philosophical Magazine 2, 559-572.

Rosner, R. and Goldberg, S. (2011a), Analysis of gw-scale overnight capital cost, Technical report, The University of Chicago. 
Rosner, R. and Goldberg, S. (2011b), Small modular reactors - key to future nuclear power generation in the u.s. Unpublished manuscript.

Zanella, S. C. F. and Mixon, F. (2000), 'Is economic freedom one dimensional? a factor analysis of some common measures of economic freedom', Journal of Economic Development 25, 17-40.

Zimmerman, M. (1982), 'Learning effects and the commercialization of new technologies: The case of nuclear power', The Bell Journal of Economics 13, 297-310. 


\section{Appendix A Cour de Comptes overnight construction cost}

\begin{tabular}{|c|c|c|c|c|}
\hline Pair of units & Capacity MW & Year & Type & Overnight Cost $(\mathrm{M} € 2010 / \mathrm{MW})$ \\
\hline \multicolumn{5}{|c|}{ Palier $900 \mathrm{MW}$} \\
\hline Fessenheim1.2 & 1780 & 1978 & CP0 & 0,836 \\
\hline Bugey2.3 & 1840 & 1979 & CP0 & 0,886 \\
\hline Bugey4.5 & 1800 & 1979 & $\mathrm{CP} 0$ & 0,899 \\
\hline Damprierre1.2 & 1800 & 1980 & $\mathrm{CP} 1$ & 1,217 \\
\hline Gravelines1.2 & 1840 & 1980 & $\mathrm{CP} 1$ & 0,822 \\
\hline Tricastin1.2 & 1840 & 1980 & CP1 & 1,188 \\
\hline Blayais1.2 & 1830 & 1982 & $\mathrm{CP} 1$ & 1,110 \\
\hline Dampierre3.4 & 1800 & 1981 & $\mathrm{CP} 1$ & 1,172 \\
\hline Gravelines3.4 & 1840 & 1981 & $\mathrm{CP} 1$ & 0,856 \\
\hline Tricastin3.4 & 1840 & 1981 & $\mathrm{CP} 1$ & 1,247 \\
\hline Blayais3.4 & 1820 & 1983 & $\mathrm{CP} 1$ & 0,890 \\
\hline Gravelines5.6 & 1820 & 1985 & $\mathrm{CP} 1$ & 1,093 \\
\hline SaintLaurent 1.2 & 1760 & 1983 & $\mathrm{CP} 2$ & 1,120 \\
\hline Chinon 1.2 & 1740 & 1984 & $\mathrm{CP} 2$ & 1,148 \\
\hline Cruas1.2 & 1760 & 1984 & $\mathrm{CP} 2$ & 1,119 \\
\hline Cruas3.4 & 1760 & 1984 & $\mathrm{CP} 2$ & 1,253 \\
\hline Chinon3.4 & 1760 & 1987 & $\mathrm{CP} 2$ & 0,978 \\
\hline \multicolumn{5}{|c|}{ Palier $1300 \mathrm{MW}$} \\
\hline Paluel1.2 & 2580 & 1985 & $\mathrm{P} 4$ & 1,531 \\
\hline Paluel3.4 & 2580 & 1986 & $\mathrm{P} 4$ & 1,157 \\
\hline St Alban 1.2 & 2600 & 1986 & $\mathrm{P} 4$ & 1,129 \\
\hline Flamanville1.2 & 2580 & 1987 & $\mathrm{P} 4$ & 1,287 \\
\hline Cattenom1.2 & 2565 & 1987 & $\mathrm{P}^{\prime} 4$ & 1,358 \\
\hline Belleville1.2 & 2620 & 1988 & $\mathrm{P}^{\prime} 4$ & 1,083 \\
\hline Cattenom3.4 & 2600 & 1991 & $\mathrm{P}^{\prime} 4$ & 1,149 \\
\hline Nogent1.2 & 2620 & 1988 & $\mathrm{P}^{\prime} 4$ & 1,194 \\
\hline Glofech1.2 & 2620 & 1992 & $\mathrm{P}^{\prime} 4$ & 1,305 \\
\hline Penly 1.2 & 2660 & 1991 & $\mathrm{P}^{\prime} 4$ & 1,227 \\
\hline \multicolumn{5}{|c|}{ Palier $1450 \mathrm{MW}$} \\
\hline Chooz1.2 & 2910 & 2000 & N4 & 1,635 \\
\hline Civaux1.2 & 2945 & 2002 & $\mathrm{~N} 4$ & 1,251 \\
\hline
\end{tabular}




\section{Appendix B Linear regression models}

We have estimated different linear regression models in order to deal with the multicollinearity problem among the explanatory variables. As possible solutions we have decided to replace capacity with dummy variables at the type or palier level. With these variables we are allowing that the changes in technology or scale translate in different intercepts. Given that we have a small sample, the introduction of a dummy variable for each type of reactor reduces substantially the degrees of freedom thus we still get non significant coefficients as we can observe in the following tables.

Table 7: Linear regression estimates with dummy for type of reactor

\begin{tabular}{cccccc}
\hline Coefficients & Estimate & Std. Error & $\mathrm{t}$ value & $\operatorname{Pr}(>|t|)$ & \\
\hline (Intercept) & 8.309 & 4.063 & 2.045 & 0.055 &. \\
CP1 & 0.202 & 0.114 & 1.768 & 0.093 &. \\
CP2 & 0.445 & 0.261 & 1.702 & 0.106 & \\
N4 & 0.704 & 0.676 & 1.042 & 0.311 & \\
P'4 & 0.618 & 0.509 & 1.215 & 0.240 & \\
P4 & 0.672 & 0.410 & 1.637 & 0.119 & \\
EXPI & 0.005 & 0.010 & 0.519 & 0.610 & \\
EXPT & 0.005 & 0.014 & 0.357 & 0.725 & \\
Ln LTime & 0.564 & 0.321 & 1.757 & 0.095 & $*$ \\
UCL & -2.221 & 0.888 & -2.501 & 0.022 & $*$ \\
US7 & -0.014 & 0.020 & -0.680 & 0.505 & \\
\hline
\end{tabular}

Table 8: VIF for the explanatory variables

\begin{tabular}{ccccc}
\hline EXPI & EXPT & LnLTime & UCL & US7 \\
\hline 8.006 & 2.721 & 3.068 & 5.697 & 1.934 \\
\hline
\end{tabular}

We have also tried a model without leadtime and overall experience in the linear regression; given that we already know that they are highly correlated with capacity. However, we still find that the coefficients are imprecisely estimated. 
Table 9: Linear regression estimates with dummy for palier

\begin{tabular}{ccccc}
\hline Coefficients & Estimate & Std. Error & $\mathrm{t}$ value & $\operatorname{Pr}(>|t|)$ \\
\hline (Intercept) & 6.014 & 3.947 & 1.524 & 0.142 \\
Palier 2 & 0.016 & 0.157 & 0.104 & 0.918 \\
Palier 3 & -0.049 & 0.271 & -0.181 & 0.857 \\
EXPI & 0.014 & 0.007 & 1.922 & 0.068 \\
EXPT & -0.008 & 0.008 & -0.983 & 0.336 \\
Ln LTime & 0.343 & 0.347 & 0.986 & 0.335 \\
UCL & -1.524 & 0.895 & -1.703 & 0.103 \\
US7 & -0.012 & 0.019 & -0.629 & 0.535 \\
\hline
\end{tabular}

Table 10: VIF for the explanatory variables

\begin{tabular}{ccccc}
\hline EXPI & EXPT & LnLTime & UCL & US7 \\
\hline 5.219 & 1.345 & 2.920 & 5.051 & 1.569
\end{tabular}

Table 11: Linear regression estimates with dummy for type and no leadtime

\begin{tabular}{ccccc}
\hline Coefficients & Estimate & Std. Error & $\mathrm{t}$ value & $\operatorname{Pr}(>|t|)$ \\
\hline (Intercept) & -0.127 & 0.078 & -1.627 & 0.118 \\
CP1 & 0.208 & 0.111 & 1.866 & 0.076 \\
CP2 & 0.259 & 0.249 & 1.040 & 0.310 \\
N4 & 0.502 & 0.604 & 0.832 & 0.415 \\
P'4 & 0.349 & 0.468 & 0.746 & 0.464 \\
P4 & 0.382 & 0.385 & 0.992 & 0.332 \\
EXPI & -0.0002 & 0.0110 & -0.020 & 0.984 \\
EXPT & -0.003 & 0.0141 & -0.217 & 0.830 \\
\hline
\end{tabular}

Table 12: VIF for the explanatory variables

\begin{tabular}{cc}
\hline EXPI & EXPT \\
\hline 2.349 & 7.610 \\
\hline
\end{tabular}


Table 13: Linear regression estimates with dummy for type and no leadtime

\begin{tabular}{cccccc}
\hline Coefficients & Estimate & Std. Error & t value & $\operatorname{Pr}(>|t|)$ & \\
\hline (Intercept) & -1.550 & 1.495 & -1.037 & 0.311 & \\
CP1 & 0.203 & 0.095 & 2.120 & 0.046 & $*$ \\
CP2 & 0.242 & 0.096 & 2.501 & 0.020 & $*$ \\
N4 & 0.289 & 0.241 & 1.199 & 0.243 & \\
P'4 & 0.236 & 0.144 & 1.640 & 0.116 & \\
P4 & 0.312 & 0.119 & 2.615 & 0.016 & $*$ \\
EXPT & -0.003 & 0.007 & -0.527 & 0.603 & \\
Ln LTime & 0.294 & 0.309 & 0.952 & 0.351 & \\
\hline
\end{tabular}

Table 14: VIF for the explanatory variables

\begin{tabular}{cc}
\hline EXPT & LnLTime \\
\hline 1.201 & 2.68 \\
\hline
\end{tabular}

\section{Appendix C Principal component regression}

In this Appendix, we show the results for different specifications for the construction cost function using the principal component regression.

In general, the results are the same. The first component have high loadings of capacity, overall experience and leadtime and it is the main driver of the cost escalation and the second represents the negative relation between experience within similar types of reactors and the safety performance indicators.

Nevertheless, when we remove the experience within palier or one of the safety variables, the criteria to select the number of principal components to keep in the estimation leads to select only the first one. Thus the share of the variance that we use to estimate is smaller; however the signs remain the same as well as the main conclusions.

In Table 15, we have the loadings and eigenvalues for the model without the variable that captures the experience at palier level, i.e $E X P P_{i}$.

As in the original model, the first component has high loading of capacity, overall experience and leadtime. Which confirms that the main 
Table 15: Eigenvectors and eigenvalues of Model without EXPP

\begin{tabular}{lrrrrrr}
\hline & Comp 1 & Comp 2 & Comp 3 & Comp 4 & Comp 5 & Comp 6 \\
\hline Ln Cap & 0.535 & -0.238 & 0.168 & -0.215 & & 0.763 \\
EXPI & 0.556 & & 0.221 & -0.131 & 0.601 & -0.512 \\
EXPT & & 0.582 & 0.639 & -0.421 & -0.269 & \\
Ln LTime & 0.553 & -0.107 & & 0.207 & -0.732 & -0.321 \\
UCL & -0.214 & -0.606 & & -0.711 & -0.173 & -0.227 \\
US7 & -0.223 & -0.475 & 0.716 & 0.460 & & \\
\hline$\lambda$ & 79.649 & 51.575 & 20.022 & 10.208 & 4.372 & 2.171 \\
\hline
\end{tabular}

driver of the cost escalation was the scale-up. The second component has high loadings from the experience constructing the same type of reactors and the safety indicators. The opposite signs support our previous result, that suggest that the latest units in each series have the best safety performances.

In this model we found that the number of components that minimize the RMSEP is one. The estimates for the standardized and original variables are presented in Table 16. We obtain the same insights that with the original model. We confirm the absence of scale effects and an overall learning curve but we have found positive learning effects when building the same type of reactors. The negative values for the estimates related to safety indicators coincide with those found in the complete model, thus reducing the events that may lead to accidents is related with higher costs.

Table 16: PC Results for model without EXPP

\begin{tabular}{lrrrrrl}
\hline Coefficients & $\hat{\beta}^{*}$ & $\hat{\beta}$ & s.e $(\hat{\beta})$ & t-value & p-value & \\
\hline Ln Cap & 0.207 & 1.0518 & $(0.266)$ & 3.939 & 0.0006 & $* * *$ \\
EXPI & 0.215 & 0.0124 & $(0.003)$ & 3.939 & 0.0006 & $* * *$ \\
EXPT & -0.021 & -0.005 & $(0.001)$ & -3.939 & 0.0006 & $* * *$ \\
Ln LTime & 0.214 & 1.003 & $(0.010)$ & -3.939 & 0.0006 & $* * *$ \\
UCL & -0.083 & -0.083 & $(0.069)$ & -3.939 & 0.0006 & $* * *$ \\
US7 & -0.086 & -0.086 & $(0.254)$ & 3.939 & 0.0006 & $* * *$ \\
\hline
\end{tabular}

We also have consider a model with only $U S 7$ as safety variable and other using $U C L$ solely. The unique difference between these models is that in the number of components that minimize the RSMSE. In the first 
one, with one component the criterion is minimized, in the second one is two.

Table 17: Eigenvectors and eigenvalues of Model without $U C L$

\begin{tabular}{lrrrrrr}
\hline & Comp 1 & Comp 2 & Comp 3 & Comp 4 & Comp 5 & Comp 6 \\
\hline LnCap & -0.568 & & 0.173 & -0.134 & 0.453 & 0.651 \\
EXPI & -0.505 & 0.301 & 0.265 & 0.284 & 0.280 & -0.652 \\
EXPP & 0.263 & 0.576 & 0.173 & 0.648 & & 0.375 \\
EXPT & 0.205 & 0.543 & 0.454 & -0.671 & & \\
US7 & & -0.521 & 0.814 & 0.172 & -0.163 & \\
Time & -0.549 & 0.103 & & & -0.823 & \\
\hline$\lambda$ & 81.020 & 48.474 & 20.52 & 13.415 & 4.431 & 0.131 \\
\hline
\end{tabular}

Table 18: PC Results for model without $U C L$

\begin{tabular}{lrrrrrr}
\hline Coefficients & $\hat{\beta}^{*}$ & $\hat{\beta}$ & $\mathrm{s} . \mathrm{e}(\hat{\beta})$ & $\mathrm{t}$-value & $\mathrm{p}$-value & \\
\hline Ln Cap & 0.208 & 1.060 & $(0.254)$ & 4.165 & $4.03 \mathrm{e}-04$ & $* * *$ \\
EXPT & 0.185 & 0.010 & $(0.002)$ & 4.165 & $4.03 \mathrm{e}-04$ & $* * *$ \\
EXPP & -0.096 & -0.010 & $(0.002)$ & -4.165 & $4.03 \mathrm{e}-04$ & $* * *$ \\
EXPI & -0.075 & -0.0181 & $(0.004)$ & -4.165 & $4.03 \mathrm{e}-04$ & $* * *$ \\
Ln LTime & 0.201 & 0.945 & $(0.227)$ & 4.165 & $4.03 \mathrm{e}-04$ & $* * *$ \\
US7 & -0.034 & -0.108 & $(0.025)$ & -4.165 & $-4.03 \mathrm{e}-04$ & $* * *$ \\
\hline
\end{tabular}

We found similar results for the other safety indicator. 
Table 19: Eigenvectors and eigenvalues of Model without US7

\begin{tabular}{lrrrrrr}
\hline & Comp 1 & Comp 2 & Comp 3 & Comp 4 & Comp 5 & Comp 6 \\
\hline Ln Cap & 0.571 & & -0.101 & -0.266 & 0.406 & -0.654 \\
EXPI & 0.501 & 0.296 & 0.329 & -0.279 & 0.223 & 0.652 \\
EXPP & -0.276 & 0.510 & 0.698 & -0.124 & -0.155 & -0.371 \\
EXPT & -0.215 & 0.521 & -0.581 & -0.558 & -0.177 & \\
UCL & & -0.602 & 0.231 & -0.690 & -0.327 & \\
LnLTime & 0.547 & 0.132 & & 0.221 & -0.789 & \\
\hline$\lambda$ & 80.616 & 57.097 & 13.797 & 12.874 & 3.473 & 0.140 \\
\hline
\end{tabular}

Table 20: PC Results for model without US7

\begin{tabular}{lrrrrrr}
\hline Coefficients & $\hat{\beta}^{*}$ & $\hat{\beta}$ & s.e $(\hat{\beta})$ & t-value & p-value & \\
\hline Ln Cap & 0.213 & 1.085 & $(0.257)$ & 4.217 & $3.549 \mathrm{e}-04$ & $* * *$ \\
EXPT & 0.227 & 0.013 & $(0.002)$ & 5.103 & $4.097 \mathrm{e}-05$ & $* * *$ \\
EXPP & -0.0267 & -0.002 & $(0.001)$ & -1.808 & $8.427 \mathrm{e}-02$ &. \\
EXPI & -0.002 & -0.001 & $(0.003)$ & 1.803 & $8.504 \mathrm{e}-02$ &. \\
Ln LTime & 0.220 & 1.0301 & $(0.227)$ & 4.525 & $1.670 \mathrm{e}-04$ & $* * *$ \\
UCL & -0.097 & -0.046 & $(0.001)$ & -45.135 & $3.498 \mathrm{e}-23$ & $* * *$ \\
\hline
\end{tabular}

